\title{
Estimation of stature from combined length of forearm and hand in Jammu region of India
}

\author{
Shahnaz Choudhary ${ }^{1 *}$, Harbans Singh $^{2}$, Neena Gupta ${ }^{3}$ \\ ${ }^{1}$ Lecturer, Postgraduate Department of Anatomy, Government Medical College Jammu, J \& K, India \\ ${ }^{2}$ Professor, Department of Anatomy, Chintpurni Medical College \& Hospital Pathankot, Punjab, India \\ ${ }^{3}$ Demonstrator, Postgraduate Department of Anatomy, Government Medical College Jammu, J \& K, India \\ *Corresponding author E-mail: schoudhary4805@yahoo.co.in
}

Copyright (-) 2014 Shahnaz Choudhary et al. This is an open access article distributed under the Creative Commons Attribution License, which permits unrestricted use, distribution, and reproduction in any medium, provided the original work is properly cited.

\begin{abstract}
Estimation of stature is a major cause of concern in forensic medicine and forensic anthropology. It becomes difficult to predict the physical identification of an individual when only fragmentary remains of dead body are brought for postmortem. Physical reconstruction from such remains depends upon the fact that various body parts exhibit consistent ratios when compared to total height of a person. Present study is an endeavor to generate formula for estimation of stature from combined length of forearm and hand in Jammu region of India. Results of present study reveal highly significant gender differences between the selected parameters necessitating the need for separate data for two sexes. A positive and significant correlation coefficient of 0.615 and 0.731 has been observed in the males and females in the present study. The regression equation for both sexes has been derived for practical use in anatomical, forensic and archeological investigations.
\end{abstract}

Keywords: Stature estimation, length of forearm and hand, regression equation.

\section{Introduction}

Stature or body height is one of the most important and useful anthropometric parameter to determine the physical identity of criminals and victims including age, sex and race [1], [2]. Increasing frequency of mass disasters like tsunamis, plane crashes, earthquakes, genocides etc. has created problems in the determination of stature and identification of victims when only fragmented or dismembered human remains are available for investigations [3], [4], [5], [6]. In such cases the forensic expert has no choice but to use a relatively less precise method of reconstruction i.e. the mathematical method which is workable even if a part of body is available [7]. For past many years scientists, anatomists and anthropologists have laid focus on dimensional relativity between various body segments [8], [9], and [10]. This relationship between body segments has been used to compare and highlight variations between ethnic groups using somatometeric measures. Somatometry, which deals with measurements of living and cadavers, forms a major tool in studying human biological variability including morphological variations. Studies of such variations by their very nature have a comparative focus in which variations within and among populations form the central theme [11]. Recent studies have observed differential limb proportions between two sexes and among different populations. For example, Negros has relatively long arms and legs [12]. Therefore the formulae derived from one population cannot be applied with accuracy for others necessitating the need to evaluate various data which are both population and sex specific. Investigations have been conducted in the last few decades to establish stature estimation from hand and feet using multiple linear regression analysis for both genders in different regions with variable degree of success [3], [6], [10], [13], [14], and [15]. This emphasizes the need for further investigation using additional parameters for accuracy and reliability. In the present study, attempt has been made to compute regression equations for determination of anthropometric relationship between body height and combined length of forearm and hand in Jammu region of India. To the best of our knowledge no data for prediction of personal stature from various segments of upper extremity is available in this region. 


\section{Materials and methods}

The present study was conducted on 100 medical students 50 males and 50 females belonging to Jammu region. The students varied in age from 18 to 21 years. The combined length of forearm and hand was measured as a straight distance between apex of olecranon process and tip of the middle finger. Left handed students were excluded from the present work to avoid any variation on two sides caused by limb dominance. The subject was asked to keep the forearm and hand on a straight table, to which a white sheet of paper was fixed. The elbow was flexed at right angle and forearm was kept in supine position. Care was taken to see that fingers and hand remains in straight line with forearm. The position of the apex of olecranon process and tip of middle finger was marked on the paper and distance between two lines was recorded with the help of the measuring tape to the nearest $\mathrm{mm}$. The height of the individual was measured with the help of an anthropometer as the distance between vertex and floor, when the person is standing in anatomical position and the head in Frankfurt plane. All measurements were taken between 1pm to 3pm to eliminate discrepancies caused by diurnal variations.

\section{Results}

Various parameters observed and their statistical interpretations have been summarized in table 1 and table 2.

Table 1: statistical differences between forearm plus hand length and height in two sexes. (All measurements are in cms)

\begin{tabular}{lllll}
\hline Parameters & Males & Females & $\mathrm{t}$ & $\mathrm{P}$ \\
\hline Height $($ mean \pm SD) & $169.76 \pm 6.23$ & $155.21 \pm 5.32$ & 12.53 & 0.0001 \\
Forearm plus hand length $($ mean \pm SD) & $46.31 \pm 2.73$ & $42.35 \pm 1.53$ & 8.91 & 0.0001 \\
\hline
\end{tabular}

Table 2: Statistical analysis of stature estimation from length of forearm plus hand. (All measurements are in $\mathrm{cms}$ )

\begin{tabular}{lll}
\hline Parameters & Males & Females \\
\hline Height range & $155.5-189.4$ & $142.0-166.9$ \\
Mean height & 169.76 & 155.21 \\
S.D of height & 6.23 & 5.32 \\
S.E of height & 0.88 & 0.75 \\
Forearm + hand length range & $36.1-52.6$ & $39.0-45.8$ \\
Mean forearm + hand length & 46.31 & 42.35 \\
S.D of forearm + hand length & 2.73 & 1.53 \\
S.E of forearm + hand length & 0.38 & 0.21 \\
Correlation coefficient(r) between & $0.615(\mathrm{P}<0.01)$ & $0.731(\mathrm{P}<0.01)$ \\
forearm + hand length \& height & 0.378 & 0.534 \\
Coefficient of determination( R) & $1.4($ S.E 0.25) & $2.54(\mathrm{~S} . \mathrm{E} \mathrm{0.34)}$ \\
Regression coefficient (b) & $104.9($ S.E 12.01) & $47.39(\mathrm{~S} . \mathrm{E} \mathrm{14.53)}$ \\
Value of constant (a) & & \\
\hline
\end{tabular}

\section{Discussion}

Ever since the formulation of multiplicative factors and regression equations for stature estimation on the bases of long limb bone dimensions by Allbrook [16], many workers have presented parameters to reconstruct stature from various skeletal remains as well as body parts. This reconstruction becomes crucial because sometimes amputated and dismembered parts of the body are found disposed off in the open, ditches, rubbish, dumps etc. at the site of crime or disaster and are brought to forensic medicine experts with the objective of identification. Studies have been conducted in the recent past on height determination from length of hand, feet, upper extremity and facial measurements in living subjects [1], [4], [10], [14]. To the best of our knowledge, the correlation between combined length of forearm plus hand has not been formulated in Indian population. The present study for the first time documents a relationship between these two variables in the local population of Jammu region for practical use in medico legal, anthropological and archeological studies. The results of present study reveal that the mean height for males is $169.76 \pm 6.23$ and for females $155.21 \pm 5.32$ and mean length of forearm plus hand in males is $46.31 \pm 2.73$ and in females is $42.35 \pm 1.53$ (TABLE 1). Statistical analysis of these figures shows that highly significant differences exist between these measurements in two sexes $(\mathrm{P}<0.0001)$, hence the need for alternate formulae for the genders. A significant and positive correlation coefficient (r) of 0.615 for males and 0.731 for females has been observed between selected parameters in the present study (TABLE.2). It is accepted principle that a body dimension which correlates highly with stature would yield more accurate determination of stature when compared to low correlation. Current course of investigative study after statistical analysis and data interpretation highlights the reliability of selected parameters in 
evaluation of stature and thus will provide an additional armamentarium in the hands of forensic experts for individual physical description when only fragmentary remains of body are available.

Following regression formula is used for calculation of height.

$\mathrm{Y}$ (height $)=$ constant $+($ regression coefficient $\times$ length of forearm plus hand $)$

Regression equations derived for two sexes are:-

For Males: $\quad$ height $=104.9+(1.4 \times 46.31)$

For Females: height $=47.39+(2.54 \times 42.35)$

\section{Conclusion}

Regression equations for determination of stature from the combined length of forearm and hand in Jammu region of India have been formulated in two sexes. These are of considerable significance for forensic experts in reconstruction of stature of an individual in medicolegal cases when only fragmentary remains of the body are available

\section{Acknowledgements}

The authors gratefully acknowledge the valuable guidance of Dr Dinesh Kumar, Assistant Professor Department of Community Medicine of this institution for going through statistical data and giving his expert opinion.

\section{References}

[1] Jibonkumar and Lilinchandra. Estimation of stature using different facial measurements among the Kabui Naga of Imphal Valley, Manipur. Anthropologist; 2006, 8 (1): 1-3.

[2] Dayal MR, Steyn M and Kuykendell KL. Stature estimation from bones of South African Whites. South Afri Jr Sci; 2008, 104 (3\&4):124-8.

[3] Jasuja OP and Singh G. Estimation of stature from hand and phalange length. J Ind Asso Forensic Med; 2004, 26 (3): 100-6.

[4] Ozaslan A, Koc S, Ozaslan I and Tugcu H. Estimation of stature from upper extremity. Mil Med; 2006, 171 (4): 288-91.

[5] Krishan K. Determination of stature from foot and its segments in a North Indian Population. Am Jr Forensic Med \& Path; 2008 , 29 (4):297303.

[6] Barnabas D and Elukpo A. Sexual dimorphism in hand and foot length,indices,stature-ratio and relationship to height in Nigerians. Internet Jr Forensic Sci; 2008, 3 (1):1-10.

[7] Bhavna and Nath S. Estimation of stature on the basis of measurements of the lower limb. Anthropologists; 2007, 3: 219-22.

[8] Bhatnagar DP, Thapar SP and Batish MK. Identification of personal height from the somatometery of the hand in Punjabi males. Forensic Sc Int; 1984, 24: 137-41.

[9] Abdel - Malek AK, Ahmad AM Sharkawi SSA and Hamid NMA. Prediction of stature from hand measurements. Forens Sc Int; 1990, 46: $181-7$.

[10] Isurani I, Ganananda N and Nadeeka P. Prediction of personal stature based on the hand length. Galle Med Jr; 2009, 14 (1):15-8.

[11] Krishan K. Anthropometery in forensic medicine and forensic science - Forensic Anthropometery. The Internet Jr Forensic Sci; 2007, 2 (1):119.

[12] Ebite LE, OzokoTC, Eveka AO, Otuaga PO, Oni AO and Om'Iniabohs FAE. Height - Ulna ratio: A method of stature estimation in a rural community in Endostate, Nigeria. Internet Jr Forensic Sci; 2008, 3 (1): 1-8.

[13] Sanli SG, Kizilkanat ED, Boyan N, Ozsahin ET, Bozkir MG, Soames R, Erol H and Oguz O. Stature estimation based on hand length and foot length. Clin Anat; 2005, 18 (8):589-96.

[14] Patel SM, Shah GV and Patel SV. Estimation of height from measurements of foot length in Gujrat region. Jr Anat Soc Ind; 2007 , 56 (1):25-7.

[15] Deopa D, Chandra P, Richa N and Jha SK. Estimation of stature from foot length in Uttarakhand region. Ind Jr Forensic Med \& Toxicology; 2010, 4 (1): online 0973-9130.

[16] Allbrook D. The estimation of stature in British and East African males based on tibial and ulnar bone lengths. J Forensic Med; 1961, 8:15-28. 